medRxiv preprint doi: https://doi.org/10.1101/2021.05.14.21255910; this version posted May 14, 2021. The copyright holder for this preprint (which was not certified by peer review) is the author/funder, who has granted medRxiv a license to display the preprint in perpetuity.

It is made available under a CC-BY 4.0 International license .

\title{
Assessing and predicting adolescent and early adulthood common mental disorders in the ALSPAC cohort using electronic primary care data
}

\author{
Daniel Smith ${ }^{1,2}$, Kathryn Willan ${ }^{3}$, Stephanie L Prady ${ }^{4}$, Josie Dickerson ${ }^{3}$, Gillian Santorelli ${ }^{3}$, Kate \\ Tilling ${ }^{1,2}$, Rosie P Cornish ${ }^{1,2}$ \\ ${ }^{1}$ MRC Integrative Epidemiology Unit at the University of Bristol, UK \\ ${ }^{2}$ Population Health Sciences, Bristol Medical School, University of Bristol, UK \\ ${ }^{3}$ Born in Bradford, Bradford Teaching Hospitals NHS Foundation Trust, Bradford, UK \\ ${ }^{4}$ Department of Health Sciences, University of York, UK
}

\begin{abstract}
Objectives: This paper has three objectives: 1) examine agreement between common mental disorders (CMDs) derived from primary health care records and repeated CMD questionnaire data from ALSPAC (the Avon Longitudinal Study of Parents and Children); 2) explore the factors affecting CMD identification in primary care records; and 3) taking ALSPAC as the reference standard, to construct models predicting ALSPAC-derived CMDs using primary care data.
\end{abstract}

Design and Setting: Prospective cohort study (ALSPAC) with linkage to electronic primary care data.

Participants: Primary care records were extracted for 11,807 ALSPAC participants (80\% of the 14,731 eligible participants). The number of participants with both linked primary care and ALSPAC CMD data varied between 3,633 (age 15/16) to 1,298 (age 21/22).

Outcome measures: Outcome measures from ALSPAC data were diagnoses of suspected depression and/or CMDs. For the primary care data, Read codes for diagnosis, symptoms and treatment were used to indicate the presence of depression and CMDs.

For each time point, sensitivities and specificities (using ALSPAC-derived CMDs as the reference standard) were calculated and the factors associated with identification of primary care-based CMDs in those with suspected ALSPAC-derived CMDs explored. Lasso models were then performed to predict ALSPAC CMDs from primary care data.

Results: Sensitivities were low for CMDs (range: 3.5 to 19.1\%) and depression (range: 1.6 to $34.0 \%$ ), while specificities were high (nearly all $>95 \%$ ). The strongest predictor of identification in the primary care data was symptom severity. The lasso models had relatively low prediction rates, especially for out-of-sample prediction (deviance ratio range: -1.3 to $12.6 \%$ ), but improved with age.

Conclusions: Even with predictive modelling using all available information, primary care data underestimate $\mathrm{CMD}$ rates compared to estimates from population-based studies. Research into the use of free-text data or secondary care information is needed to improve the predictive accuracy of models using clinical data.

Keywords: ALSPAC, Common Mental Disorders, Depression, Primary Care Data, Data Linkage, Predictive Modelling

NOTE: This preprint reports new research that has not been certified by peer review and should not be used to guide clinical practice. 
medRxiv preprint doi: https://doi.org/10.1101/2021.05.14.21255910; this version posted May 14, 2021. The copyright holder for this preprint (which was not certified by peer review) is the author/funder, who has granted medRxiv a license to display the preprint in perpetuity.

It is made available under a CC-BY 4.0 International license .

\section{Strengths and limitations of this study}

- We used a large prospective cohort (ALSPAC) and were able to link these data to individuals' electronic primary care records, with this linkage data covering $\sim 80 \%$ of the cohort.

- We used validated mental health questionnaires to assess depression and common mental disorders among the ALSPAC cohort, which we treat as our 'reference standard'.

- We were able to assess agreement between ALSPAC data and electronic primary care data for common mental disorders across adolescence and into adulthood, a key life transition and period where mental health problems often emerge.

- There is a risk of selection bias, as many participants with primary care data did not have ALSPAC mental health measures, while primary care data coverage also decreased with age; continued participation in both cases is likely to be non-random.

- For this study we assumed that the common mental disorder data from ALSPAC are the 'reference standard' against which the primary care data should be compared; however, this data may also be subject to misclassification.

- The available linkage data consisted of primary care Read codes, which misses data from other clinical sources, such as secondary care or from primary care free-text data. 
medRxiv preprint doi: https://doi.org/10.1101/2021.05.14.21255910; this version posted May 14, 2021. The copyright holder for this preprint

(which was not certified by peer review) is the author/funder, who has granted medRxiv a license to display the preprint in perpetuity.

It is made available under a CC-BY 4.0 International license .

\section{Introduction}

Common mental disorders (CMDs; depression and anxiety) are a leading cause of morbidity, disability and premature death worldwide [1]. Rates of CMDs have increased over the past few decades [2], including in adolescence and early adulthood [3], where these conditions frequently first appear [4,5]. The prevalence of CMDs in childhood and adolescence (age 5-16) in the UK is estimated to be $4 \%$ [6], rising to $16 \%$ among $16-24$ year-olds [7]; these can have significant longterm consequences, including on education, quality-of-life, employment and physical and mental health $[5,8,9]$.

Assessing the prevalence of CMDs in the population, especially in adolescence, is essential for monitoring, research and planning of appropriate public health services. Estimates of prevalence could be from population studies (which are expensive and time-consuming to conduct), or using primary (General Practitioner; GP) and secondary (hospital and specialised healthcare services) care records [10-13]. However, CMDs are often under-diagnosed in routine primary care data (the socalled 'clinical iceberg' phenomenon), with over half of all depressed patients with clinical symptoms of depression not recognised as such $[14,15]$. Reasons for this include: individuals with CMDs not visiting their GP [16]; GPs misdiagnosing, or being reticent in diagnosing, CMDs [15]; and GPs increasingly recording symptoms, rather than specific diagnoses [17]. This 'clinical iceberg' may be particularly prevalent among children and adolescents, who may be less likely to visit their GP. Additionally, GPs may fail to identify, or be less willing to diagnose CMDs or prescribe antidepressants to these groups [18-20]. Primary care physicians frequently refer to secondary care services, such as Child and Adolescent Mental Health Services (CAMHS; [21]), again contributing to the under-reporting of adolescent CMDs in primary care records.

To assess the accuracy of primary care-derived CMD rates, these must be compared against a reference standard [16]. A systematic review in adults found that, relative to a reference standard, specificity is generally high (few false positives) but sensitivity is rather low (many false negatives; [12]). Previous research from the Avon Longitudinal Study of Parents and Children (ALSPAC) compared linked primary care records at age 17/18 against CMDs measured on 1,562 participants via the revised Clinical Interview Schedule (CIS-R) [10]. Using CIS-R as the reference standard, this study found that - similar to findings in adults - sensitivities were low while specificities were high. Together, these findings suggest that primary care data may significantly underestimate the prevalence of CMDs in the population.

Previous UK research has shown that greater symptom severity is the strongest predictor of attending primary care regarding mental health [16]. Other factors, such as age, sex and employment status, also predicted accessing primary care, but their contributions were weaker [16]. In contrast, a smaller US study of individuals with depressive symptoms found no demographic differences between those who sought help and those who did not, although symptom severity again predicted help-seeking behaviour [22]. Sociodemographic factors may play a role in access to primary care, recognition of symptoms, and access to treatment, which contribute to continuing health inequalities $[23,24]$. For instance, a UK study found that both non-British ethnicity and low socioeconomic position predicted lower rates of CMD detection in primary care records during the maternal period [25]. Even if individuals with a CMD do contact a physician, the likelihood of receiving treatment is also dependent on symptom severity, as well as socio-demographic factors $[26,27]$.

Models predicting 'true' CMD status from variables available in primary care records could help to identify the prevalence of individuals with 'missing' CMDs as well as the factors predicting these 
medRxiv preprint doi: https://doi.org/10.1101/2021.05.14.21255910; this version posted May 14, 2021. The copyright holder for this preprint (which was not certified by peer review) is the author/funder, who has granted medRxiv a license to display the preprint in perpetuity.

It is made available under a CC-BY 4.0 International license .

cases. Previous work has predicted CMDs based on an Australian dataset [28], but did not use primary care records, so its utility may be limited as some relevant factors are unlikely to be present in routine health records (e.g., job satisfaction, social isolation, being a carer, having a partner, etc.). Research using only primary care record data to predict validated measures of CMDs from population-based studies are therefore required.

This study has three aims:

1) Replicate and expand the results of a previous ALSPAC study at age $17 / 18(\sim 2,800$ participants [10]) by including additional participants with linkage data ( 12,000 participants $[29,30])$, and explore agreement between primary care records and cohort data across multiple time points over adolescence and young adulthood (ages 15-23).

2) Assess the factors impacting rates of identification in primary care records.

3) Construct a prediction model, with ALSPAC-measured CMDs as the outcome, to predict CMD status using only primary care data.

\section{Methods}

\section{Study Design and Participants}

ALSPAC is a pregnancy-based longitudinal birth cohort which recruited pregnant women in the Bristol area of southwest England with an expected delivery date between 1st April 1991 and 31st December 1992 [31,32]. AS total of 14,541 eligible pregnancies were initially recruited into the study, with a total of 14,676 foetuses, resulting in 14,062 live births, of which 13,988 were alive at one year of age. After further waves of post-natal recruitment, as of February 2019 there are a total of 14,901 study child participants enrolled in ALSPAC who were alive at one year [30]. These children and their parents have been followed since birth, with detailed data collected via questionnaires, inperson clinic assessments, and linkage to routine data sets. The study website contains details of all available data through a fully searchable data dictionary and variable search tool:

http://www.bristol.ac.uk/alspac/researchers/our-data/. From 22 years onwards data were collected and managed using REDCap electronic data capture tools hosted at the University of Bristol [33].

When the study children reached legal adulthood (age 18), ALSPAC initiated a postal fair processing campaign to formally re-enrol the children into the study (prior to this parent-based consent was mandatory, although from age 9 children assented to data collection as well) and to simultaneously seek opt-out permission for ALSPAC to link to their health and administrative records [34]. Linkage to primary care records was carried out following this campaign and electronic primary care records have been extracted for nearly 12,000 study children [30]. This linkage is described in more detail in the supplementary material (see also [29]).

In total, 14,731 ALSPAC participants were eligible for our study, comprising all enrolled singletons and twins who were alive at 1 year of age and had not withdrawn consent from the study. Of this total sample, 13,113 participants were sent fair processing materials, of which 368 (2.8\%) dissented to linkage. Primary care records (although not necessarily for the entire time period) were extracted for 11,807 of these individuals ( $80 \%$ of the original 14,731 eligible participants; $90 \%$ of the 13,113 sent fair processing materials). Note that there are several dynamic factors that affect inclusion eligibility in these analyses (e.g., study enrolment status and linkage quality to the NHS Person Demographics Service, PDS). Therefore, the numbers reported here may differ from the numbers reported in the ALSPAC primary care linkage data note (currently in preparation). 
medRxiv preprint doi: https://doi.org/10.1101/2021.05.14.21255910; this version posted May 14, 2021. The copyright holder for this preprint (which was not certified by peer review) is the author/funder, who has granted medRxiv a license to display the preprint in perpetuity.

It is made available under a CC-BY 4.0 International license .

The current study includes ALSPAC data from multiple time points between the ages of 15 and 23 (table 1), from either clinic or questionnaire data collections. The age 15/16 and $17 / 18$ clinics collected data on both depression and anxiety; at the other time points only depression was assessed. Linked primary care record data coverage decreases with age because the linkage data primarily covers the Bristol area; as many participants moved away as they reached adulthood (e.g. for university or work) they are lost from the linked dataset.

Table 1: Details of ALSPAC data used and coverage with primary care linkage data.

\begin{tabular}{|l|l|l|l|}
\hline Age (time point) & Measure & $\begin{array}{l}\text { \# with ALSPAC } \\
\text { CMD data }\end{array}$ & $\begin{array}{l}\text { \# of these with } \\
\text { primary care data (\%) }\end{array}$ \\
\hline $\begin{array}{l}\text { Age 15/16 (TF3 } \\
\text { clinic) }\end{array}$ & DAWBA (Depression \& anxiety) & 5,332 & $3,663(68.7 \%)$ \\
\hline $\begin{array}{l}\text { Age 16/17 (CCS } \\
\text { questionnaire) }\end{array}$ & SMFQ (Depression only) & 4,950 & $3,213(64.9 \%)$ \\
\hline $\begin{array}{l}\text { Age 17/18 (TF4 } \\
\text { clinic) }\end{array}$ & CIS-R (Depression \& anxiety) & 4,534 & $3,084(68 \%)$ \\
\hline $\begin{array}{l}\text { Age 18/19 (CCT } \\
\text { questionnaire) }\end{array}$ & SMFQ (Depression only) & 3,302 & $1,982(60 \%)$ \\
\hline $\begin{array}{l}\text { Age 21/22 (YPA } \\
\text { questionnaire) }\end{array}$ & SMFQ (Depression only) & 3,283 & $1,298(39.5 \%)$ \\
\hline $\begin{array}{l}\text { Age 22/23 (YPB } \\
\text { questionnaire) }\end{array}$ & SMFQ (Depression only) & 3,896 & $1,325(34 \%)$ \\
\hline
\end{tabular}

DAWBA: Development and Well-Being Assessment; SMFQ: Short Mood and Feelings Questionnaire; CIS-R: Clinical Interview Schedule - Revised.

\section{Patient and Public Involvement Statement}

ALSPAC has an advisory panel of $>30$ participants who meet bimonthly to advise on study design, methodology and acceptability. ALSPAC communicates with participants via regular newsletters and has an active website and social media presence.

\section{ALSPAC data}

At the age 15/16 clinic, depression and anxiety were assessed using the Development and WellBeing Assessment (DAWBA) interview [35], which estimates the probability of several psychiatric diagnoses in children and adolescents (based on International Classification of Diseases-10 (ICD-10) and Diagnostic and Statistical Manual of Mental Disorders fourth edition (DSM-IV) criteria). Here, we designated an estimated probability of depression of $>50 \%$ as a diagnosis for depression, and defined CMDs as an estimated probability of $>50 \%$ for depression and/or any anxiety disorder (generalised anxiety disorder, panic disorder, agoraphobia, social phobia and specific phobias).

At the 17/18 clinic, depression and anxiety were assessed using a self-administered computerised CIS-R questionnaire [36]. As with DAWBA, CIS-R can be used to assign ICD-10 diagnoses of depression and anxiety disorders [37]. Here, the criteria of mild depression (which included moderate and severe depression) was used as a diagnosis of depression, while a diagnosis of CMD was defined as meeting the criteria for mild depression and/or an anxiety disorder (generalised anxiety disorder, mixed anxiety and depression, panic disorders and phobic disorders). 
medRxiv preprint doi: https://doi.org/10.1101/2021.05.14.21255910; this version posted May 14, 2021. The copyright holder for this preprint (which was not certified by peer review) is the author/funder, who has granted medRxiv a license to display the preprint in perpetuity.

It is made available under a CC-BY 4.0 International license .

At the other ages (16/17, 18/19, 21/22 and 22/23 questionnaires), depression was assessed using a self-administered Short Mood and Feelings Questionnaire (SMFQ), a 13-item questionnaire assessing depressive symptoms over the past two weeks [38]. Total SMFQ scores range between 0-26, with a score of 12 or more frequently used as a diagnosis of depression [39]. Although there are problems of inaccuracy with using cut-offs from questionnaires as screening tools for depression [40], using ALSPAC data the validity of the SMFQ during childhood and adolescence was found to be high when compared against ICD-10-derived depression diagnoses from CIS-R at age 17/18 [41]. Only participants who answered all 13 SMFQ questions were included in the analyses.

To compare sociodemographic differences between those with and without linked primary care data and to explore whether demographic factors impact rates of identification in primary care records, several variables measured during pregnancy or at birth and known to be predictive of non-response in ALSPAC were utilised [31,32]. These include child sex; maternal age, home ownership status; marital status and parity; parental education levels; and child ethnicity. Additional variables used for aims 2 and 3 are discussed below.

\section{Electronic primary care data}

The linked primary care data comprised Read codes V.2 ( 5 byte), along with associated dates. Read codes relevant to diagnosis, symptoms or treatment (antidepressants, anxiolytics and hypnotics) of depression or anxiety (including phobic disorders) were extracted $[10,11]$. These were combined to produce three definitions of depression and CMDs (table 2). Based on previous research [10], these were chosen to include the definitions with the lowest sensitivity ('current diagnosis, treated'), the highest sensitivity ('current diagnosis or treatment or symptoms'), and an intermediate sensitivity which is also the most straightforward to extract from primary care records ('current diagnosis'). 'Current' diagnoses, symptoms or treatment were defined as being 6 months either side of the age the study child attended the clinic or completed the questionnaire and 'historical' as having occurred at least 6 months prior to the age at the clinic/questionnaire. Note that treatment does not include psychological therapies, even though these are the recommended first line of treatment for adolescents, as these therapies are mainly given by specialist secondary mental health services and may not be noted in primary care records. Read codes were used to identify referrals to mental health services. A list of the Read codes used are provided in supplementary table S1.

Table 2: Details of the multiple definitions of 'depression' and 'CMD' derived from the primary care data.

\begin{tabular}{|l|l|}
\hline Definition & Description \\
\hline Current diagnosis & Current diagnosis of depression/CMD \\
\hline Current diagnosis, treated & $\begin{array}{l}\text { Current diagnosis of depression/CMD and currently } \\
\text { receiving treatment }\end{array}$ \\
\hline $\begin{array}{l}\text { Current diagnosis or treatment or } \\
\text { symptoms }\end{array}$ & $\begin{array}{l}\text { Current diagnosis or symptoms or treatment for } \\
\text { depression/CMD }\end{array}$ \\
\hline
\end{tabular}

Additional data were extracted to predict identification in primary care records and for the prediction models. These primary care variables may be associated with our outcomes of interest, and included: average annual number of GP consultations and prescriptions at the relevant time 
medRxiv preprint doi: https://doi.org/10.1101/2021.05.14.21255910; this version posted May 14, 2021. The copyright holder for this preprint

(which was not certified by peer review) is the author/funder, who has granted medRxiv a license to display the preprint in perpetuity.

It is made available under a CC-BY 4.0 International license .

point; current and historical somatic and general symptoms (defined in supplementary table S1); referral to mental health services; common chronic health conditions (asthma and eczema); other mental health conditions (eating disorders, ADHD, conduct disorder, autistic spectrum disorder, alcohol and drug abuse, schizophrenia, bipolar disorder and psychosis); family and personal history of depression and mental health issues; self-harm; and smoking status (described in more detail below).

To ensure that only individuals with primary care data at the relevant time points were included, inclusion criteria were: i) having associated linkage data; ii) having primary care data for at least 6 months after their clinic visit or questionnaire completion (based on GP registration dates); and iii) first appearing in the primary care records a minimum of 18 months prior to their clinic visit or questionnaire completion (allowing a 6 month window for 'current' data, plus a whole year previous for 'historical' data).

\section{Statistical Analysis}

For each primary care definition and at each time point, sensitivity, specificity and positive and negative predictive values were calculated separately for depression and CMDs (if measured), using the ALSPAC questionnaire data as the reference standard. Exact $95 \%$ confidence intervals were derived using binomial probabilities.

We then explored factors associated with identification of $\mathrm{CMDs} /$ depression in primary care records for individuals diagnosed in the ALSPAC data. As primary care diagnosis numbers were low, we used the definition with the highest sensitivity ('current diagnosis or symptoms or treatment'). Univariate logistic regression was used to explore whether each covariate was associated with identification. The variables used to predict identification were a combination of ALSPAC and primary care data (for a full list see table S2). These identification analyses were repeated for each timepoint, separately for both depression and CMD (if measured).

Finally, lasso (Least Absolute Selection and Shrinkage Operator) models were used at each time point to assess the combination of variables from primary care data which best predicted depression/CMDs from the ALSPAC data. Lasso models apply a lambda weight which constrains weakly-predictive variables falling below this value to zero, while also shrinking remaining non-zero coefficients towards zero. This results in sparse models which minimise over-fitting, and can subsequently be used for out-of-sample prediction [42,43]. Ten-fold cross-validation was used for all lasso models and visual inspection of the cross-validation plots were performed to assess that the optimal lambda value had been selected.

We randomly split our sample into $60 \%$ training and $40 \%$ validation samples, and then compared the deviance ratios (a goodness-of-fit statistic comparable to $R^{2}$, but for non-linear models) for each to inspect how well the training model performed when predicting depression/CMDs in the validation sample. Logistic lasso models were used with ALSPAC-derived depression or CMDs at each time point as the outcome variable, and all variables in table $\mathrm{S} 3$ as predictors.

To assess whether these models, which utilise all the available information held in primary care records, increase model fit relative to just the primary care diagnosis/symptoms/treatment data, we compared these models against: i) a prediction model which just contained 'current diagnosis' as a predictor variable; and ii) a prediction model which included 'current diagnosis', 'current symptoms' 
medRxiv preprint doi: https://doi.org/10.1101/2021.05.14.21255910; this version posted May 14, 2021. The copyright holder for this preprint (which was not certified by peer review) is the author/funder, who has granted medRxiv a license to display the preprint in perpetuity.

It is made available under a CC-BY 4.0 International license .

and 'current treatment' as predictor variables. In- and out-of-sample deviance ratios of these models were compared to assess model fit.

For each time point, from the models utilising all the available primary care data we also calculated the predicted probabilities of receiving a depression or CMD diagnosis (with a threshold of $>50 \%$ probability to define diagnosis) in the $40 \%$ validation sample, and compared sensitivities and specificities derived from these prediction models against the three definitions using the raw primary care data (table 2). All analyses were conducted using Stata v.16.0.

\section{Results}

\section{Demographics and Linkage Data Coverage}

Table 1 shows numbers with both linkage and ALSPAC data at each time point (the reasons individuals who have ALSPAC data, but do not have linkage data, are provided in table S4). The proportion of unlinked records increases with age, most likely because these individuals left the area as they became adults.

Comparisons between those with ALSPAC data who do and do not have primary care data are presented in tables 3 (for age 15/16 and 22/23 time points) and S5 (for all other time points). There are some differences, particularly in terms of socio-economic position (e.g., less likely to have primary care data if higher parental education levels), but little difference in terms of sex. At later time points, participants with more GCSEs or equivalents are less likely to have primary care data. Few differences in depression/CMD diagnosis are apparent between these two groups. With the exception of $\mathrm{CMD} /$ depression diagnoses (which increases with age) differences in demographics across the time points are minimal, although the proportion of females with ALSPAC data does increase over time.

Figure 1 gives the proportions with a current diagnosis of depression/CMD in the primary care data comparing those who did to those who did not complete the ALSPAC clinic or questionnaire. Those with ALSPAC data are more likely to have a current CMD diagnosis, particularly at the later time points. For depression, those with ALSPAC data are slightly more likely to have a primary care diagnosis at ages $21 / 22$ and $22 / 23$ but there are no differences at earlier time points. 
Table 3: Demographics at the age 15/16 clinic and 22/23 questionnaire time points. Of those with ALSPAC data, the table compares those who have primary care data against those who do not. For categorical variables cells are counts and percentages. For continuous variables cells are means and standard deviations. Note also that the denominators vary as the variables come from different data sources, with different levels of completeness. As the demographics are broadly similar across all time points, only the first and last time point are presented here (see table 55 for all other time points).

\begin{tabular}{|c|c|c|c|c|}
\hline & \multicolumn{2}{|c|}{ Age 15/16 (TF3 clinic) - DAWBA (CMDs and Depression) } & \multicolumn{2}{|c|}{ Age 22/23 (YPB questionnaire) - SMFQ (Depression) } \\
\hline & Primary care data $(n=3663)$ & $\begin{array}{l}\text { No primary care data } \\
(n=1669)\end{array}$ & $\begin{array}{l}\text { Primary care data } \\
(n=1325)\end{array}$ & No primary care data $(n=2571)$ \\
\hline \multicolumn{5}{|l|}{ Sex } \\
\hline Male & $1748(47.7 \%)$ & $782(46.9 \%)$ & $474(35.8 \%)$ & $868(33.8 \%)$ \\
\hline Female & $1915(52.3 \%)$ & $887(53.2 \%)$ & $851(64.2 \%)$ & $1703(66.2 \%)$ \\
\hline Maternal age at child's birth & $29.2(4.6)$ & $29.3(4.6)$ & $29.2(4.5)$ & $29.6(4.4)$ \\
\hline \multicolumn{5}{|c|}{ Mother's home ownership status } \\
\hline $\begin{array}{l}\text { Owned/ } \\
\text { Mortgaged }\end{array}$ & $2878(85.3 \%)$ & $1292(83.8 \%)$ & $998(84.2 \%)$ & $2022(85.5 \%)$ \\
\hline Rented & $137(4.1 \%)$ & $90(5.8 \%)$ & $58(4.9 \%)$ & $121(5.1 \%)$ \\
\hline $\begin{array}{l}\text { Council/Housing } \\
\text { Association }\end{array}$ & $281(8.3 \%)$ & $111(7.2 \%)$ & $100(8.4 \%)$ & $151(6.4 \%)$ \\
\hline Other & $79(2.3 \%)$ & $48(3.1 \%)$ & $30(2.5 \%)$ & $70(3 \%)$ \\
\hline \multicolumn{5}{|l|}{ Mother's marital status } \\
\hline Never married & $460(13.5 \%)$ & $211(13.6 \%)$ & $152(12.6 \%)$ & $262(11 \%)$ \\
\hline Single/Divorced & $147(4.3 \%)$ & $83(5.3 \%)$ & $50(4.2 \%)$ & $105(4.4 \%)$ \\
\hline First marriage & 2607 (76.5\%) & $1149(74 \%)$ & $918(76.2 \%)$ & $1851(77.7 \%)$ \\
\hline $2^{\text {nd }} / 3^{\text {rd }}$ marriage & $194(5.7 \%)$ & $110(7.1 \%)$ & 85 (7.1\%) & $164(6.9 \%)$ \\
\hline \multicolumn{5}{|l|}{ Mother's parity } \\
\hline 0 & $1623(48.1 \%)$ & $787(51.3 \%)$ & $560(47 \%)$ & $1155(49.1 \%)$ \\
\hline 1 & $1201(35.6 \%)$ & $507(33.1 \%)$ & $413(34.7 \%)$ & $815(34.7 \%)$ \\
\hline $\mathbf{2}$ or more & $554(16.4 \%)$ & $240(15.7 \%)$ & $218(18.3 \%)$ & $381(16.2 \%)$ \\
\hline \multicolumn{5}{|c|}{ Mother's highest education level } \\
\hline O level/lower & $1884(55.2 \%)$ & $765(49.3 \%)$ & $748(62.8 \%)$ & $1071(45.5 \%)$ \\
\hline A level & $920(27.3 \%)$ & $476(30.7 \%)$ & $280(23.5 \%)$ & $770(30.6 \%)$ \\
\hline Degree & $565(16.8 \%)$ & $312(20.1 \%)$ & $164(13.8 \%)$ & $562(23.9 \%)$ \\
\hline \multicolumn{5}{|l|}{ Father's highest education level } \\
\hline O level/lower & $1428(46.2 \%)$ & 559 (39.3\%) & $550(50.5 \%)$ & 795 (35.9\%) \\
\hline A level & 947 (30.6\%) & $437(30.6 \%)$ & $348(32 \%)$ & $653(29.5 \%)$ \\
\hline
\end{tabular}




\begin{tabular}{|c|c|c|c|c|}
\hline Degree & $716(23.2 \%)$ & $429(30.1 \%)$ & $191(17.5 \%)$ & $767(34.6 \%)$ \\
\hline \multicolumn{5}{|l|}{ Child ethnicity } \\
\hline White & $3179(95.9 \%)$ & $1466(95.8 \%)$ & $1138(96.8 \%)$ & $2237(96.2 \%)$ \\
\hline Non-white & $137(4.1 \%)$ & $65(4.3 \%)$ & $38(3.2 \%)$ & $88(3.8 \%)$ \\
\hline \# GCSEs (or equivalents) & $7.3(3.6)$ & $7.5(3.6)$ & $7.3(3.5)$ & $8.3(3.2)$ \\
\hline \multicolumn{5}{|c|}{ ALSPAC depression diagnosis } \\
\hline No & $3606(98.4 \%)$ & $1638(98.1 \%)$ & $1103(83.2 \%)$ & $2180(84.6 \%)$ \\
\hline Yes & $57(1.6 \%)$ & $31(1.9 \%)$ & $223(16.8 \%)$ & $398(14.5 \%)$ \\
\hline \multicolumn{5}{|c|}{ ALSPAC common mental disorder (CMD) diagnosis } \\
\hline No & $3540(96.6 \%)$ & $1622(97.2 \%)$ & - & - \\
\hline Yes & $123(3.4 \%)$ & $47(2.8 \%)$ & - & - \\
\hline
\end{tabular}

DAWBA: Development and Well-Being Assessment; CMDs: Common mental disorders; SMFQ: Short Mood and Feelings Questionnaire. 
medRxiv preprint doi: https://doi.org/10.1101/2021.05.14.21255910; this version posted May 14, 2021. The copyright holder for this preprint (which was not certified by peer review) is the author/funder, who has granted medRxiv a license to display the preprint in perpetuity.

It is made available under a CC-BY 4.0 International license .

Figure 1: Comparing primary care common mental disorder (CMD) and depression rates in participants with vs without ALSPAC data at each time point. For participants who did not attend the clinic/complete the questionnaire, the age to define a 'current' diagnosis was based on +/- 6 months from the average age each clinic/questionnaire was completed. Individuals who have primary care data and attended/completed the clinic/questionnaire, but do not have ALSPAC-derived depression/CMD data (as this session was not completed for whatever reason), are not included in the figure below. Full details of these numbers, and the data for this figure, are provided in table S6.

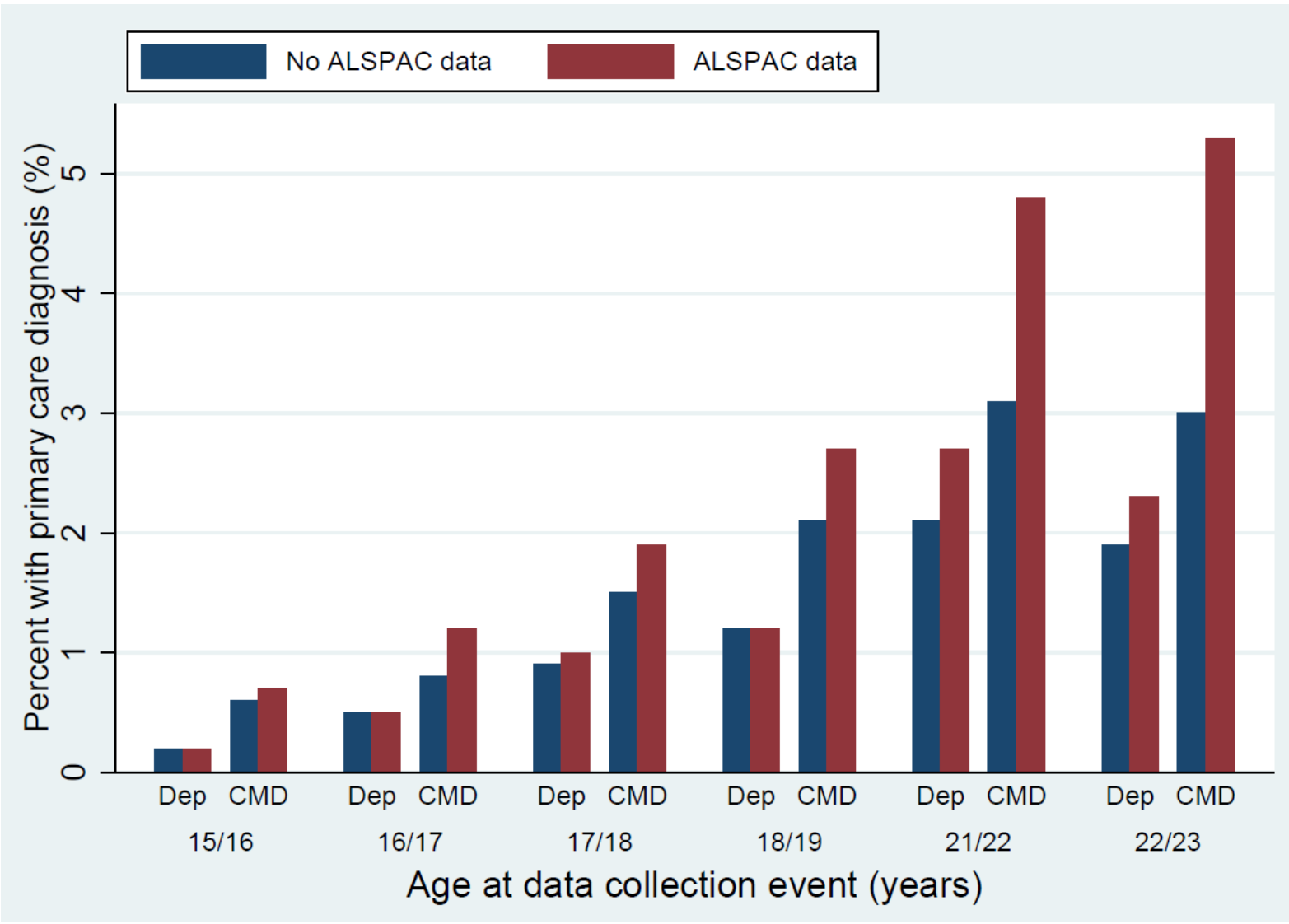

Sensitivity, Specificity and Predictive Values

We focused first on the age $17 / 18$ clinic data (table 4), the results of which were broadly consistent with previous ALSPAC analyses [10]. At this age, 243/3,084 participants (7.9\%) were diagnosed as depressed using the CIS-R data, while 455 (14.8\%) met the criteria for diagnosis of CMD. Using the various primary care definitions, the number of individuals diagnosed as depressed ranged from a minimum of $20(0.7 \%)$ using a definition of 'current diagnosis, treated', to a maximum of $122(4 \%)$ using a definition of 'current diagnosis or symptoms or treatment'. Thus, the sensitivity of each primary care definition was low, ranging from $3.7 \%$ to $24.3 \%$. Specificity was higher (all > $97.8 \%$ ), as was the negative predictive values (NPVs; all >92\%), while positive predictive values (PPVs) ranged between $45 \%$ and $58.4 \%$. For the primary care CMD data, numbers diagnosed ranged from a minimum of $29(0.9 \%)$ to a maximum of $171(5.5 \%)$. CMD sensitivity (range: $3.5-19.1 \%$ ) and specificity (all > 96.8\%) were marginally lower compared to depression at this age, while each PPV was slightly higher (range: 47.4-55.2\%) and NPV lower (range: 85.6-87.4\%).

Similar results were found for the age 15/16 clinic using the DAWBA measure (table S7), albeit with fewer depression and CMD diagnoses and lower sensitivities. The comparison between SMFQ 
medRxiv preprint doi: https://doi.org/10.1101/2021.05.14.21255910; this version posted May 14, 2021. The copyright holder for this preprint (which was not certified by peer review) is the author/funder, who has granted medRxiv a license to display the preprint in perpetuity.

It is made available under a CC-BY 4.0 International license.

questionnaire data and primary care data at ages 16/17, 18/19, 21/22 and 22/23 are displayed in supplementary tables S8 to S11, and were similar to those using DAWBA (age 15/16 clinic) and CIS-R (age 17/18 clinic), with relatively high specificity but low sensitivity for all primary care definitions of depression. Sensitivity increased with age, while specificity decreased (figure 2).

Table 4: Depression and CMD diagnoses based on the CIS-R (clinical interview schedule - revised) data from the age 17/18 TF4 clinic against various definitions derived from the primary care data at this age $(n=3,084)$. This table also includes sensitivities, specificities, positive predictive values (PPV) and negative predictive values (NPV) for the depression and common mental disorder (CMD) diagnoses based on the CIS-R data from this clinic. In these analyses we are treating the ALSPAC data as the reference standard.

\begin{tabular}{|c|c|c|c|c|c|c|c|}
\hline \multirow{2}{*}{ Primary care definition } & & \multicolumn{3}{|c|}{ CIS-R Depression } & \multicolumn{3}{|c|}{ CIS-R CMD } \\
\hline & & No & Yes & Total & No & Yes & Total \\
\hline \multirow[t]{2}{*}{ Current diagnosis } & No & 2,825 & 229 & 3,054 & 2,599 & 428 & 3,027 \\
\hline & Yes & 16 & 14 & 30 & 30 & 27 & 57 \\
\hline Sensitivity & & \multicolumn{3}{|c|}{$5.8 \%(3.2 ; 9.5)$} & \multicolumn{3}{|c|}{$5.9 \%(3.9 ; 8.5)$} \\
\hline Specificity & & \multicolumn{3}{|c|}{$99.4 \%(99.1 ; 99.7)$} & \multicolumn{3}{|c|}{$98.9 \%(98.4 ; 99.2)$} \\
\hline Positive Predictive Value & & \multicolumn{3}{|c|}{$46.7 \%(28.3 ; 65.7)$} & \multicolumn{3}{|c|}{$47.4 \%(34 ; 61)$} \\
\hline \multirow[t]{2}{*}{ Negative Predictive Value } & & \multicolumn{3}{|c|}{$92.5 \%(91.5 ; 93.4)$} & \multicolumn{3}{|c|}{$85.9 \%(84.6 ; 87.1)$} \\
\hline & & No & Yes & Total & No & Yes & Total \\
\hline \multirow[t]{2}{*}{ Current diagnosis, treated } & No & 2,830 & 234 & 3,064 & 2,616 & 439 & 3,055 \\
\hline & Yes & 11 & 9 & 20 & 13 & 16 & 29 \\
\hline Sensitivity & & \multicolumn{3}{|c|}{$3.7 \%(1.7 ; 6.9)$} & \multicolumn{3}{|c|}{$3.5 \%(2 ; 5.6)$} \\
\hline Specificity & & \multicolumn{3}{|c|}{$99.6 \%$ (99.3; 99.8) } & \multicolumn{3}{|c|}{$99.5 \%$ (99.2; 99.7) } \\
\hline Positive Predictive Value & & \multicolumn{3}{|c|}{$45 \%(23.1 ; 68.5)$} & \multicolumn{3}{|c|}{$55.2 \%(35.7 ; 73.6)$} \\
\hline Negative Predictive Value & & \multicolumn{3}{|c|}{$92.4 \%(91.4 ; 93.3)$} & \multicolumn{3}{|c|}{$85.6 \%(84.3 ; 86.9)$} \\
\hline & & No & Yes & Total & No & Yes & Total \\
\hline \multirow{2}{*}{$\begin{array}{l}\text { Current diagnosis or symptoms or } \\
\text { treatment }\end{array}$} & No & 2,778 & 184 & 2,962 & 2,545 & 368 & 2,913 \\
\hline & Yes & 63 & 59 & 122 & 84 & 87 & 171 \\
\hline Sensitivity & & \multicolumn{3}{|c|}{$24.3 \%(19 ; 30.2)$} & \multicolumn{3}{|c|}{$19.1 \%(15.6 ; 23)$} \\
\hline Specificity & & \multicolumn{3}{|c|}{$97.8 \%(97.2 ; 98.3)$} & \multicolumn{3}{|c|}{$96.8 \%(96.1 ; 97.4)$} \\
\hline Positive Predictive Value & & \multicolumn{3}{|c|}{$48.4 \%(39.2 ; 57.6)$} & \multicolumn{3}{|c|}{$50.9 \%(43.1 ; 58.6)$} \\
\hline Negative Predictive Value & & \multicolumn{3}{|c|}{$93.8 \%(92.9 ; 94.6)$} & \multicolumn{3}{|c|}{$87.4 \%(86.1 ; 88.6)$} \\
\hline
\end{tabular}


medRxiv preprint doi: https://doi.org/10.1101/2021.05.14.21255910; this version posted May 14, 2021. The copyright holder for this preprint (which was not certified by peer review) is the author/funder, who has granted medRxiv a license to display the preprint in perpetuity.

It is made available under a CC-BY 4.0 International license .

Figure 2: Sensitivity, specificity and positive/negative predicted values for depression (black) and common mental disorders (CMDs; red) over each of the time points studies. Results are based on the definition 'current diagnosis, symptoms or treatment' to determine cases in primary care records, treating the ALSPAC data as the reference standard. Note that CMDs were only assessed at the age $15 / 16$ and $17 / 18$ clinics.
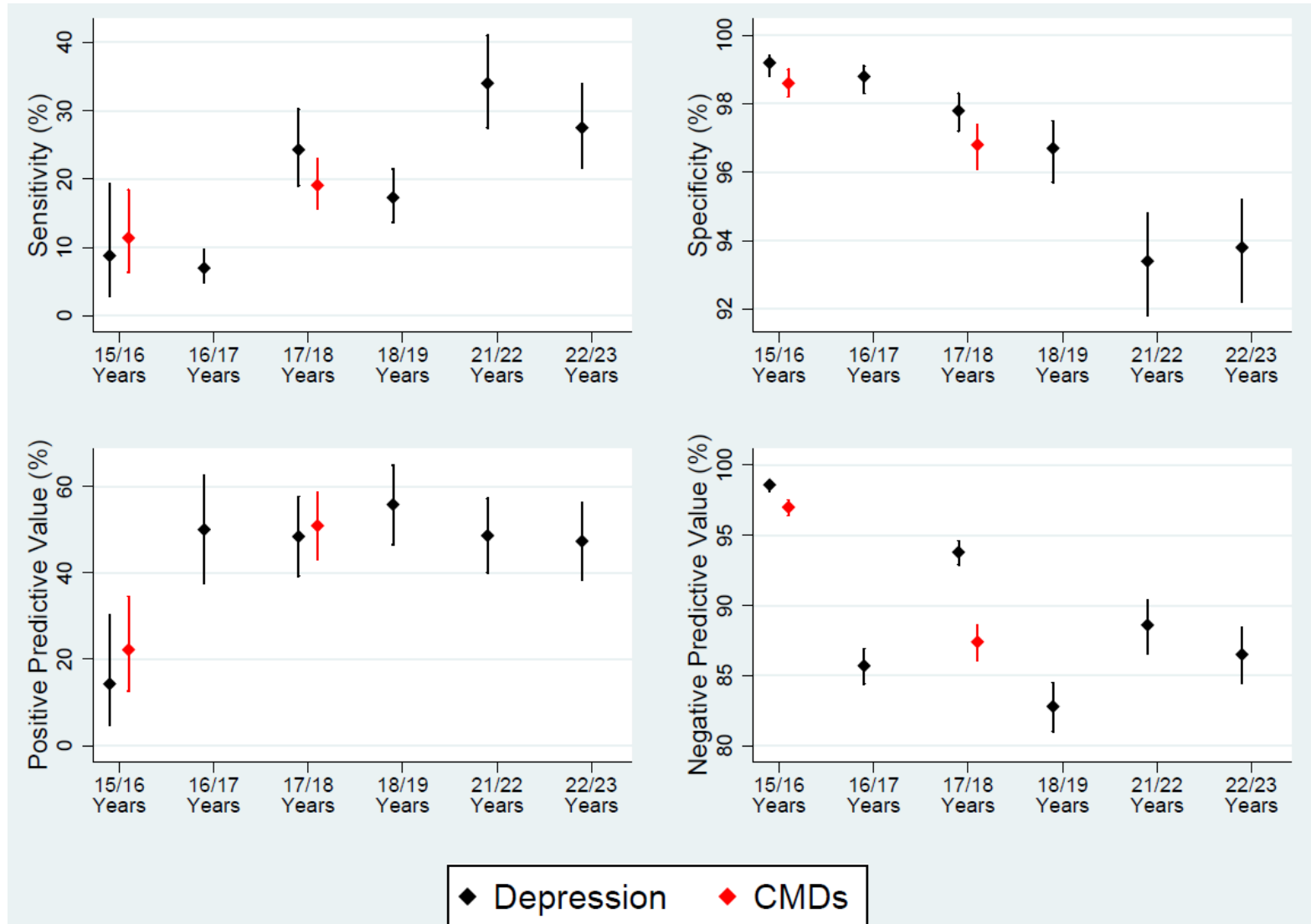

\section{Identification of CMDs/Depression Cases in Primary Care Records}

The results of the primary care records identification analyses are presented in full in table S12 (giving odds ratios and 95\% confidence intervals for all analyses) and figure S1 (providing a graphical summary of key results over each time point). There are few consistent associations of sociodemographic factors (parental education, child sex, child education, etc.) with being identified as a case in the primary care records. Primary care case identification was more likely in participants with greater symptom severity. Some primary care covariates (e.g., smoking status, eating disorder and other mental health issues) were associated with higher rates of primary care case identification at younger ages, but had weaker associations at later ages. Others (somatic and general symptoms, higher consultation/prescription rates, referrals to mental health services and self-harm status) were consistently associated with higher rates of primary care case identification. Due to the low numbers diagnosed as having CMD or depression at the age 15/16 clinic, both from the DAWBA assessment and from primary care records, results from this time point should be treated with caution. 
medRxiv preprint doi: https://doi.org/10.1101/2021.05.14.21255910; this version posted May 14, 2021. The copyright holder for this preprint (which was not certified by peer review) is the author/funder, who has granted medRxiv a license to display the preprint in perpetuity.

It is made available under a CC-BY 4.0 International license .

\section{Predicting ALSPAC CMDs/Depression from Primary Care Records}

The in-sample deviance ratios, fitted on the $60 \%$ training sample, and the out-of-sample deviance ratios, fitted on the $40 \%$ validation sample, for each time point are displayed in table 5 . In general, in-sample deviance ratios are quite low (8.3 to $14.6 \%)$. Out-of-sample deviance ratios are lower (-1.3 to $12.6 \%$ ) but do increase with age. The penalised coefficients from these prediction models are presented in table S13, with full models to estimate predicted probabilities given in table S14. Many factors from the primary care data consistently predicted ALSPAC CMD/depression diagnoses across many time points, including: being female, a history of self-harm, number of GP consultations, referral to mental health services and historical and/or current depression diagnoses/symptoms/treatment. Several associations were time point specific, occurring in only one or two models (e.g., smoking at TF4 depression and CCS, eczema for TF4 depression, conduct disorder at CCS, etc.). These coefficients should not be interpreted causally, especially is there is high collinearity between variables (as is likely to be present here given that many variables measure similar constructs).

Table 5: In-sample and out-of-sample deviance ratios predicting depression and common mental disorders (CMDs) for each time point using all the available primary care data. Deviance ratios are taken from logistic cross-validation lasso prediction models.

\begin{tabular}{|c|c|c|c|c|c|c|c|c|}
\hline & \multicolumn{2}{|c|}{$\begin{array}{l}\text { Age 15/16 TF3 } \\
\text { clinic ( } n= \\
3,663)\end{array}$} & \multirow{2}{*}{$\begin{array}{l}\text { Age 16/17 } \\
\text { CCS quest. } \\
\text { ( } n=3,213) \\
\text { Dep. }\end{array}$} & \multicolumn{2}{|c|}{$\begin{array}{l}\text { Age } 17 / 18 \\
\text { TF4 clinic (n } \\
=3,084)\end{array}$} & \multirow{2}{*}{$\begin{array}{l}\text { Age 18/19 } \\
\text { CCT quest. } \\
\text { ( } n=1,982) \\
\text { Dep. }\end{array}$} & \multirow{2}{*}{$\begin{array}{l}\text { Age } 21 / 22 \\
\text { YPA quest. } \\
\text { (n=1,298) } \\
\text { Dep. }\end{array}$} & \multirow{2}{*}{$\begin{array}{l}\text { Age 22/23 } \\
\text { YPB quest. } \\
\text { ( } n=1,325) \\
\text { Dep. }\end{array}$} \\
\hline & Dep. & CMD & & Dep. & CMD & & & \\
\hline $\begin{array}{l}\text { In-sample } \\
\text { deviance ratio } \\
\text { (60\% training } \\
\text { sample) }\end{array}$ & $9.9 \%$ & $8.4 \%$ & $8.3 \%$ & $14.6 \%$ & $9.2 \%$ & $9 \%$ & $11.7 \%$ & $13.4 \%$ \\
\hline $\begin{array}{l}\text { Out-of-sample } \\
\text { deviance ratio } \\
\text { ( } 40 \% \\
\text { validation } \\
\text { sample) }\end{array}$ & $-1.3 \%$ & $2.9 \%$ & $4.3 \%$ & $7.8 \%$ & $7.8 \%$ & $8 \%$ & $12.6 \%$ & $9.1 \%$ \\
\hline
\end{tabular}

For all time points other than age 15/16 clinic depression, the 'full' prediction model (based on the set of all primary care variables; table S3) performed better than both the 'diagnosis only' and 'diagnosis/symptoms/ treatment' models for both in-sample and out-of-sample prediction (table S15).

Sensitivities from these prediction models were marginally higher than for definitions of 'current diagnosis' and 'current diagnosis with treatment', but lower than the 'current diagnosis or treatment or symptoms' sensitivities. However, the specificities of the prediction models were greater than the 'current diagnosis or treatment or symptoms' definition, and on par with the stricter definitions based on 'current diagnosis' or 'current diagnosis with treatment' (table S16). These prediction models therefore appear to more accurately detect cases of depression/CMD compared to these more stringent definitions from the primary care records, while also avoiding many of the false negatives associated with broader definitions (such as 'current diagnosis or treatment of symptoms'). However, sensitivities from these prediction models are still rather low, ranging between $3.5 \%$ and $16.3 \%$ (all specificities are $>98 \%$ ). 
medRxiv preprint doi: https://doi.org/10.1101/2021.05.14.21255910; this version posted May 14, 2021. The copyright holder for this preprint (which was not certified by peer review) is the author/funder, who has granted medRxiv a license to display the preprint in perpetuity.

It is made available under a CC-BY 4.0 International license .

\section{Discussion}

This study compared primary care data against validated measures of CMDs at multiple time points during adolescence and young adulthood. Taking ALSPAC data as the reference standard, our results demonstrate that, regardless of how CMDs are defined from primary care records, sensitivities are low across all ages (range: 1.6 to 34\%). However, detection of CMDs in primary care records does improve with age. Specificities were high, with most above $95 \%$. This suggests that the primary care data is likely to contain many 'false negatives' but few 'false positives', as documented previously [12].

This study also explored the factors predicting identification of "cases" (as identified in ALSPAC data) in primary care data. Consistent with previous research $[16,22]$, the strongest predictor was symptom severity, with individuals displaying more severe symptoms increasingly likely to be correctly classified. A history of CMDs, as well as increased rates of other mental health issues, somatic or general symptoms and engagement with primary care services (consultation and prescription rates), also predicted greater primary care identification rates. Many adolescents receive mental health care via specialised secondary care services, rather than through their GP, and this is reflected in referrals to secondary mental health services also being associated with higher identification rates. Unlike for the wider adult population, we found little evidence that sociodemographic factors were consistently associated with case identification in primary care records for adolescents and young adults $[25,44]$.

Finally, this paper also presented a series of prediction models, which can be used by epidemiologists with access only to primary care data to predict CMDs in individuals who may not be formally diagnosed by a GP. Although the variance explained by these models is quite low, these models demonstrate that the inclusion of additional covariates from primary care records improved model fit, relative to models that contained only current diagnosis, symptoms or treatment. Out-ofsample prediction rates increased with age, suggesting that these models better predict depression/CMDs in young adulthood compared to adolescence. This is perhaps not surprising, given that rates of diagnoses from primary care data are low in adolescence and increase with age. However, comparison of the predicted sensitivities and specificities from these prediction models indicates that the improvement in detection of depression/CMDs relative to the primary care record data based on diagnosis, symptoms and treatment is minimal.

\section{Strengths and Limitations}

A strength of this study is that it uses established methods to systematically define CMDs from primary care records $[10,11]$, allowing cross-study comparisons. This study uses a larger sample than a previous study using ALSPAC adolescent data [10], and extends the age range assessed to adolescence through to early adulthood. This permits a broader view of how both ALSPAC-derived and primary care-derived CMD rates change with age, how sensitivities and specificities vary over the transition to adulthood, and how prediction models alter over this developmental stage. A further strength is that this study also uses a large, deeply-phenotyped cohort, with depression and CMD measured at multiple time points using validated instruments.

This study has several limitations. The primary care data coding used may miss crucial information: possible diagnoses and symptoms may be noted within the 'free text' of routine electronic records [12], which are generally not available for research purposes [45]. The primary care data only records pharmacological treatments prescribed by the GP, rather than psychological treatments 
medRxiv preprint doi: https://doi.org/10.1101/2021.05.14.21255910; this version posted May 14, 2021. The copyright holder for this preprint (which was not certified by peer review) is the author/funder, who has granted medRxiv a license to display the preprint in perpetuity.

It is made available under a CC-BY 4.0 International license .

provided by secondary care services. As the first line of treatment for adolescents is often psychological therapies, especially for mild depression [46]), this may partially explain the lower sensitivities at younger ages. Although we included CAMHS referrals in our identification analyses and prediction models, this is still likely to underestimate the true prevalence of adolescent CMDs as only around one-third of children with a mental health disorder are referred to CAMHS [21]. Further, fewer than half of referrals to CAMHS in the UK are from a GP [47], with school nurses, self-referrals and other routes to CAMHS possible.

A second limitation is that the linkage is primarily Bristol-based. As the cohort reaches adulthood they are more likely to move away from Bristol; as such, the proportion with linkage data drops from approximately two-thirds before age 18 to roughly one-third after this age. In addition to the resulting loss of statistical power and precision, there is also the potential for selection bias if those with linkage data systematically differ from those without $[48,49]$. At each time point, of those with ALSPAC data there are differences between those with and without linked primary care data in terms of socioeconomic position (e.g., higher maternal education levels are associated with lower probability of having linkage data). Although differences in ALSPAC-derived CMDs appear minimal comparing those with vs without primary care data (table 3 ), it is possible that primary care data may differ between these groups. This may limit the generalisability of our prediction models; for example, compared to the whole ALSPAC cohort our sample with primary care data is biased towards those with a lower socioeconomic position, who may be less likely to attend GP appointments [50]. However, as in the wider ALSPAC cohort respondents tend to be from higher socioeconomic strata [32], the impact of linkage data biased towards lower-SEP (socioeconomic position) individuals on generalisability is uncertain. Comparing the primary care-derived CMD status of those with and without ALSPAC data we observe few differences in terms of depression or CMDs at younger ages but, in adulthood, CMDs (although less so for depression) appear more prevalent among those with ALSPAC data (figure 1). One possible interpretation of this is that it reflects the demographics of ALSPAC respondents, as being female is associated with continued ALSPAC participation [32], and females are at greater risk of CMDs [51,52]. When adjusting for sex these effects were somewhat attenuated, although participants with ALSPAC data at the 21/22 and 22/23 questionnaire time points were still more likely to have a primary care-derived CMD (table S17). Inclusion of parental education (a proxy for SEP), which may also predict both continued ALSPAC participation and mental health, did not further diminish this effect. The selection pressures associated with having continued primary care linkage data in ALSPAC are likely to be complex and require further investigation to assess the potential for selection bias when using this data.

A related limitation is that as the research is specifically Bristol-based, generalisability to other populations, both in the UK and elsewhere, should be made with caution. For instance, the ALSPAC cohort is not representative of the UK national population, as ALSPAC contains a greater proportion of white and higher SEP individuals [32], which is likely to shape health-seeking behaviour and GP engagement rates $[24,25]$. A further issue regarding generalisability is that the data in adolescence was collected between 2006 and 2011. Given the large shift in societal values towards increased visibility, awareness and understanding of mental health issues over the past few years, this may impact both GP decision-making and adolescents' health-seeking behaviour, potentially affecting diagnosis rates in this age group. Additional research is necessary to explore this among existing adolescents. As such, these models should be calibrated before use in other areas or calendar times.

A third limitation is the small numbers of individuals with CMD/depression in ALSPAC, especially at younger ages (and particularly the age 15/16 clinic data). This may explain why we failed to detect consistent sociodemographic differences in case identification, contrary to previous research with 
medRxiv preprint doi: https://doi.org/10.1101/2021.05.14.21255910; this version posted May 14, 2021. The copyright holder for this preprint

(which was not certified by peer review) is the author/funder, who has granted medRxiv a license to display the preprint in perpetuity.

It is made available under a CC-BY 4.0 International license .

larger samples $[16,25,44]$. Larger studies are required to explore sociodemographic associations with identification in primary care records in greater detail, which - if present - are likely to be weaker than the effects of symptom severity $[16,22]$. In addition to the relatively small sample size, one potential reason for the lack of SEP gradient could be that SEP is based on parental SEP at the time of the study child's birth. Although parental SEP and child health outcomes are frequently correlated, this association is strongest in early childhood and tends to weaken with age [24]. Assessing the individual's SEP directly, particularly in early adulthood, may reveal these health inequalities.

A further limitation is that we have taken the ALSPAC data as the 'reference standard'. These measures may over-diagnose the presence of CMDs, especially in 'borderline' cases with less severe symptoms who may not visit their GP, thus increasing the number of false positives in the ALSPAC data. Although all of the instruments used in ALSPAC have been validated and are routinely used to screen for depression and CMDs [35,36,38,41], previous studies have demonstrated that these questionnaire-based tools can provide quite divergent diagnoses of mental health conditions compared to standard clinical interviews (e.g., CIS-R; [37]). Additionally, apparent false negatives may also appear in the ALSPAC data if individuals are successfully receiving treatment to alleviate their CMD symptoms; in these cases, individuals would be diagnosed as having CMD via primary care records, but not via ALSPAC data.

\section{Implications and Recommendations}

Consistent with previous research [12], this study has demonstrated that the rate of false negatives for CMDs in adolescents and young adults in routine primary care data is high. Thus, additional sources of information need to be utilised when working with routine health data. As fewer than half of referrals to CAMHS are from GPs [47], using linkage data from CAMHS and other secondary mental health care services would likely increase detection rates. This would appear particularly important for adolescents, as the sensitivities at this age are much lower than in early adulthood. However, as CAMHS is over-subscribed, often only severe cases are accepted, potentially biasing these sources towards those with more severe CMD symptoms. Additionally, even in early adulthood sensitivities are still rather low (maximum $34 \%$ at age $21 / 22$ ), suggesting that additional information is required to correctly identify CMDs in linkage data. One potential source of information is from the free-text fields in primary care records, which are not usually made available for research purposes [12]. However, although evidence suggests that using free text data can improve detection of medical conditions more generally [53], the current evidence for CMDs - albeit limited to a small number of studies - suggests their inclusion only marginally improves detection rates [12].

\section{Conclusion}

We have demonstrated how routine electronic primary care data can be used with cohort study data to estimate the size of the 'clinical iceberg' of undetected CMDs in primary care data throughout adolescence and early adulthood, and to describe the characteristics of those less likely to be identified as cases in primary care records. Although overall sensitivities were low, both sources of data accurately predicted individuals with more severe CMD symptoms. The number of individuals diagnosed as having a CMD, and the correspondence between ALSPAC and primary care data, increased with age. Additional sources of data - e.g., from secondary care services such as CAMHS, 
medRxiv preprint doi: https://doi.org/10.1101/2021.05.14.21255910; this version posted May 14, 2021. The copyright holder for this preprint (which was not certified by peer review) is the author/funder, who has granted medRxiv a license to display the preprint in perpetuity.

It is made available under a CC-BY 4.0 International license .

or from free text fields - might be required to determine CMD prevalence more accurately, particularly in adolescence. Development of further prediction models may improve estimation of prevalence of CMDs from primary care records and help target interventions to individuals with CMDs who would otherwise not be identified as cases in primary care records. 
medRxiv preprint doi: https://doi.org/10.1101/2021.05.14.21255910; this version posted May 14, 2021. The copyright holder for this preprint (which was not certified by peer review) is the author/funder, who has granted medRxiv a license to display the preprint in perpetuity.

It is made available under a CC-BY 4.0 International license .

\section{Acknowledgements}

We are extremely grateful to all the families who took part in this study, the midwives for their help in recruiting them, and the whole ALSPAC team, which includes interviewers, computer and laboratory technicians, clerical workers, research scientists, volunteers, managers, receptionists and nurses.

\section{Contributors}

RPC, KT, SLP, KW, GS and JD conceived and designed the study. RPC processed the primary care data. DS performed the statistical analyses and drafted the manuscript. RPC, KT, SLP, KW, GS and JD contributed to the interpretation of the results. All authors commented on the draft, and have read and approved the final version of the manuscript.

\section{Funding}

This work was funded by the Medical Research Council (MRC grant number: MC_PC_17210). The UK Medical Research Council and Wellcome (Grant ref: 217065/Z/19/Z) and the University of Bristol provide core support for ALSPAC. A comprehensive list of grants funding is available on the ALSPAC website http://www.bristol.ac.uk/alspac/external/documents/grant-acknowledgements.pdf); collection of ALSPAC CMD data was funded by the NIH (grant references 5R01MH073842-04 and PD301198-SC101645; for the TF3 DAWBA and YPB MFQ data), Wellcome Trust (grant reference 08426812/Z/07/Z; for the TF4 CIS-R data), and a joint Wellcome Trust and MRC grant (grant reference 092731; for the CCS, CCT and YPA SMFQ data). This publication is the work of the authors and Daniel Smith and Rosie Cornish will serve as guarantors for the contents of this paper.

\section{Competing interests}

None declared.

Data availability statement

Information about access to ALSPAC data is given on the ALSPAC website (http://www.bristol.ac.uk/alspac/researchers/access/).

\section{Ethics approval}

Ethical approval for the study was obtained from the ALSPAC Ethics and Law Committee and the Local Research Ethics Committees (NHS Haydock REC: 10/H1010/70). Informed consent for the use of data collected via questionnaires and clinics was obtained from participants following the recommendations of the ALSPAC Ethics and Law Committee at the time.

\section{Supplementary material}

Supplementary material supporting this manuscript is available here: XXXX. 
medRxiv preprint doi: https://doi.org/10.1101/2021.05.14.21255910; this version posted May 14, 2021. The copyright holder for this preprint (which was not certified by peer review) is the author/funder, who has granted medRxiv a license to display the preprint in perpetuity.

It is made available under a CC-BY 4.0 International license .

\section{References}

1 Ferrari AJ, Charlson FJ, Norman RE, et al. Burden of Depressive Disorders by Country, Sex, Age, and Year: Findings from the Global Burden of Disease Study 2010. PLoS Med 2013;10. doi:10.1371/journal.pmed.1001547

2 Pearson RM, Carnegie RE, Cree C, et al. Prevalence of Prenatal Depression Symptoms Among 2 Generations of Pregnant Mothers: The Avon Longitudinal Study of Parents and Children. JAMA Netw open 2018;1:e180725. doi:10.1001/jamanetworkopen.2018.0725

3 Collishaw S, Maughan B, Natarajan L, et al. Trends in adolescent emotional problems in England: A comparison of two national cohorts twenty years apart. J Child Psychol Psychiatry Allied Discip 2010;51:885-94. doi:10.1111/j.1469-7610.2010.02252.x

Lewinsohn PM, Clarke GN, Seeley JR, et al. Major Depression in Community Adolescents: Age at Onset, Episode Duration, and Time to Recurrence. J. Am. Acad. Child Adolesc. Psychiatry. 1994;33:809-18. doi:10.1097/00004583-199407000-00006

Patel V, Flisher AJ, Hetrick S, et al. Mental health of young people: a global public-health challenge. Lancet 2007;369:1302-13. doi:10.1016/S0140-6736(07)60368-7

Green $\mathrm{H}$, McGinnity A, Meltzer $\mathrm{H}$, et al. Mental health of children and young people in Great Britain, 2004. 2005. doi:10.1037/e557702010-001

McManus S, Meltzer H, Brugha T, et al. Adult psychiatric morbidity in England, 2007: Results of a household survey. 2009. doi:10.13140/2.1.1563.5205

Bhatia SK, Bhatia SC. Childhood and adolescent depression. Am Fam Physician 2007;75:7380. doi:10.1192/bjp.153.4.476

Harvey SB, Henderson M, Lelliott $P$, et al. Mental health and employment: Much work still to be done. Br J Psychiatry 2009;194:201-3. doi:10.1192/bjp.bp.108.055111

Cornish R, John A, Boyd A, et al. Defining adolescent common mental disorders using electronic primary care data: A comparison with outcomes measured using the CIS-R. BMJ Open 2016;6. doi:10.1136/bmjopen-2016-013167

John A, McGregor J, Fone D, et al. Case-finding for common mental disorders of anxiety and depression in primary care: An external validation of routinely collected data. BMC Med Inform Decis Mak 2016;16:1-10. doi:10.1186/s12911-016-0274-7

12 Larvin H, Peckham E, Prady SL. Case-finding for common mental disorders in primary care using routinely collected data: a systematic review. Soc Psychiatry Psychiatr Epidemiol 2019;54:1161-75. doi:10.1007/s00127-019-01744-4

13 Davis KAS, Sudlow CLM, Hotopf M. Can mental health diagnoses in administrative data be used for research? A systematic review of the accuracy of routinely collected diagnoses. $B M C$ Psychiatry 2016;16:1-11. doi:10.1186/s12888-016-0963-x

14 Coyne JC, Schwenk TL, Fechner-Bates S. Nondetection of depression by primary care physicians reconsidered. Gen Hosp Psychiatry 1995;17:3-12. doi:10.1016/01638343(94)00056-J

15 Cepoiu M, McCusker J, Cole MG, et al. Recognition of depression by non-psychiatric physicians - A systematic literature review and meta-analysis. J Gen Intern Med 2008;23:2536. doi:10.1007/s11606-007-0428-5 
medRxiv preprint doi: https://doi.org/10.1101/2021.05.14.21255910; this version posted May 14, 2021. The copyright holder for this preprint (which was not certified by peer review) is the author/funder, who has granted medRxiv a license to display the preprint in perpetuity.

It is made available under a CC-BY 4.0 International license .

and the use of primary care services. Psychol Med 2000;30:1359-67. doi:10.1080/0954026021000046029

17 Rait G, Walters K, Griffin M, et al. Recent trends in the incidence of recorded depression in primary care. Br J Psychiatry 2009;195:520-4. doi:10.1192/bjp.bp.108.058636

Wijlaars LPMM, Nazareth I, Petersen I. Trends in depression and antidepressant prescribing in children and adolescents: A cohort study in the health improvement network (THIN). PLOS One 2012;7. doi:10.1371/journal.pone.0033181

Iliffe S, Williams G, Fernandez V, et al. General practitioners' understanding of depression in young people: Qualitative study. Prim Heal Care Res Dev 2008;9:269-79. doi:10.1017/S1463423608000868

O'Brien D, Harvey K, Howse J, et al. Barriers to managing child and adolescent mental health problems: A systematic review of primary care practitioners' perceptions. Br J Gen Pract 2016;66:e693-707. doi:10.3399/bjgp16X687061

21 Sayal K. Annotation: Pathways to care for children with mental health problems. J Child Psychol Psychiatry Allied Discip 2006;47:649-59. doi:10.1111/j.1469-7610.2005.01543.x

Henderson JG, Pollard CA, Jacobi KA, et al. Help-seeking patterns of community residents with depressive symptoms. J Affect Disord 1992;26:157-62.

23 Fryers T, Melzer D, Jenkins R. Social inequalities and the common mental disorders - A systematic review of the evidence. Soc Psychiatry Psychiatr Epidemiol 2003;38:229-37. doi:10.1007/s00127-003-0627-2

24 Adler NE, Stewart J. Health disparities across the lifespan: Meaning, methods, and mechanisms. Ann N Y Acad Sci 2010;1186:5-23. doi:10.1111/j.1749-6632.2009.05337.x

25 Prady SL, Pickett KE, Petherick ES, et al. Evaluation of ethnic disparities in detection of depression and anxiety in primary care during the maternal period: Combined analysis of routine and cohort data. BrJ Psychiatry 2016;208:453-61. doi:10.1192/bjp.bp.114.158832

26 Bebbington $\mathrm{P}$, Brugha $\mathrm{T}$, Meltzer $\mathrm{H}$, et al. Neurotic disorders and the receipt of psychiatric treatment. Psychol Med 2000;30:1369-76. doi:10.1080/0954026021000046010

27 Prady SL, Pickett KE, Gilbody S, et al. Variation and ethnic inequalities in treatment of common mental disorders before, during and after pregnancy: Combined analysis of routine and research data in the Born in Bradford cohort. BMC Psychiatry 2016;16:1-13. doi:10.1186/s12888-016-0805-x

28 Fernandez A, Salvador-Carulla L, Choi I, et al. Development and validation of a prediction algorithm for the onset of common mental disorders in a working population. Aust N Z J Psychiatry 2018;52:47-58. doi:10.1177/0004867417704506

29 Cornish RP, Macleod J, Boyd A, et al. Factors associated with participation over time in the Avon Longitudinal Study of Parents and Children: a study using linked education and primary care data. Int J Epidemiol 2020;:1-10. doi:10.1093/ije/dyaa192

Northstone K, Lewcock M, Groom A, et al. The Avon Longitudinal Study of Parents and Children (ALSPAC): an update on the enrolled sample of index children in 2019 [version 1; peer review: 2 approved]. Wellcome Open Res 2019;4:1-10. doi:10.12688/wellcomeopenres.15132.1

31 Fraser A, Macdonald-wallis C, Tilling K, et al. Cohort profile: The avon longitudinal study of parents and children: ALSPAC mothers cohort. Int J Epidemiol 2013;42:97-110. 
medRxiv preprint doi: https://doi.org/10.1101/2021.05.14.21255910; this version posted May 14, 2021. The copyright holder for this preprint (which was not certified by peer review) is the author/funder, who has granted medRxiv a license to display the preprint in perpetuity.

It is made available under a CC-BY 4.0 International license .

doi:10.1093/ije/dys066

32 Boyd A, Golding J, Macleod J, et al. Cohort profile: The 'Children of the 90s'-The index offspring of the avon longitudinal study of parents and children. Int J Epidemiol 2013;42:11127. doi:10.1093/ije/dys064

33 Harris PA, Taylor R, Thielke R, et al. Research electronic data capture (REDCap)-A metadatadriven methodology and workflow process for providing translational research informatics support. J Biomed Inform 2009;42:377-81. doi:10.1016/j.jbi.2008.08.010

Boyd A, Tilling K, Cornish R, et al. Professionally designed information materials and telephone reminders improved consent response rates: Evidence from an RCT nested within a cohort study. J Clin Epidemiol 2015;68:877-87. doi:10.1016/j.jclinepi.2015.03.014

Goodman R, Ford T, Richards H, et al. The Development and Well-Being Assessment: Description and Initial Validation of an Integrated Assessment of Child and Adolescent Psychopathology. J Child Psychol Psychiatry 2000;41:645-55. doi:10.1111/j.14697610.2000.tb02345.x

Lewis G, Pelosi AJ, Araya R, et al. Measuring psychiatric disorder in the community: A standardized assessment for use by lay interviewers. Psychol Med 1992;22:465-86. doi:10.1017/S0033291700030415

37 Brugha TS, Bebbington PE, Jenkins $\mathrm{R}$, et al. Cross validation of a general population survey diagnostic interview: A comparison of CIS-R with SCAN ICD-10 diagnostic categories. Psychol Med 1999;29:1029-42. doi:10.1017/S0033291799008892

38 Angold A, Costello EJ, Messer SC, et al. Development of a short questionnaire for use in epidemiological studies of depression in children and adolescents. Int J Methods Psychiatr Res 1995;5:237-49.

39 Thabrew H, Stasiak K, Bavin LM, et al. Validation of the Mood and Feelings Questionnaire (MFQ) and Short Mood and Feelings Questionnaire (SMFQ) in New Zealand help-seeking adolescents. Int J Methods Psychiatr Res 2018;27:1-9. doi:10.1002/mpr.1610

Roseman M, Kloda LA, Saadat N, et al. Accuracy of Depression Screening Tools to Detect Major Depression in Children and Adolescents: A Systematic Review. Can J Psychiatry 2016;61:746-57. doi:10.1177/0706743716651833

41 Turner N, Joinson C, Peters TJ, et al. Validity of the Short Mood and feelings questionnaire in late adolescence. Psychol Assess 2014;26:752-62. doi:10.1037/a0036572

42 Hastie T, Tibshirani R, Wainwright M. Statistical Learning with Sparsity: The Lasso and Generalizations. CRC Press 2015.

43 Tibshirani R. Regression Shrinkage and Selection via the Lasso. J R Stat Soc Ser B Stat Methodol 1996;58:267-88.

44 McManus S, Bebbington P, Jenkins R, et al. Mental health and wellbeing in England: Adult Psychiatric Morbidity Survey 2014. Leeds: 2016. doi:10.1079/9781786393401.0000

45 Price SJ, Stapley SA, Shephard E, et al. Is omission of free text records a possible source of data loss and bias in Clinical Practice Research Datalink studies? A case-control study. BMJ Open 2016;6:1-7. doi:10.1136/bmjopen-2016-011664

46 NICE. Depression in children and young people: Identification and management. 2019. doi:10.1211/CP.2018.20204575 
medRxiv preprint doi: https://doi.org/10.1101/2021.05.14.21255910; this version posted May 14, 2021. The copyright holder for this preprint (which was not certified by peer review) is the author/funder, who has granted medRxiv a license to display the preprint in perpetuity.

It is made available under a CC-BY 4.0 International license .

47 Children's Commissioner for England. Lightning Review: Access to Child and Adolescent Mental Health Services, May 2016. London, UK: 2016.

https://www.childrenscommissioner.gov.uk/publication/lightning-review-access-to-childand-adolescent-mental-health-services/ (accessed 3/3/2020)

48 Hernán M, Robins J. Causal Inference: What If. Boca Raton: : Chapman \& Hall/CRC Press 2020.

49 Munafò MR, Tilling K, Taylor AE, et al. Collider scope: When selection bias can substantially influence observed associations. Int J Epidemio/ 2018;47:226-35. doi:10.1093/ije/dyx206

50 Ellis DA, McQueenie R, McConnachie A, et al. Demographic and practice factors predicting repeated non-attendance in primary care: a national retrospective cohort analysis. Lancet Public Heal 2017;2:e551-9. doi:10.1016/S2468-2667(17)30217-7

51 Leach LS, Christensen H, Mackinnon AJ, et al. Gender differences in depression and anxiety across the adult lifespan: The role of psychosocial mediators. Soc Psychiatry Psychiatr Epidemiol 2008;43:983-98. doi:10.1007/s00127-008-0388-z

52 McLean CP, Asnaani A, Litz BT, et al. Gender differences in anxiety disorders: Prevalence, course of illness, comorbidity and burden of illness. J Psychiatr Res 2011;45:1027-35. doi:10.1016/j.jpsychires.2011.03.006

53 Ford E, Carroll JA, Smith HE, et al. Extracting information from the text of electronic medical records to improve case detection: A systematic review. J Am Med Informatics Assoc 2016;23:1007-15. doi:10.1093/jamia/ocv180 